\title{
DISASTER NURSING: LOOKING TO THE FUTURE IN NORWAY
}

\author{
GUNN-MARI HOLDO ${ }^{1,2}$, LEE MILES ${ }^{2} \&$ HEATHER HARTWELL ${ }^{2}$ \\ ${ }^{1}$ Faculty of Health, University of Troms $\varnothing$, Norway. \\ ${ }^{2}$ Faculty of Management, Bournemouth University, England.
}

\begin{abstract}
Health resilience is an integral part of disaster management and lies at the nexus between this and public health considerations. As the largest group of professionals worldwide, nurses face continual challenges in further developing their competences in disaster response and recovery. This paper investigates the trajectory, role and future expectations of the Norwegian nursing profession in health emergency and disaster planning, and offers a future research agenda for those interested in investigating the complex inter-relationship between disaster management and nursing. The paper seeks to respond to observations made in a recent Norwegian report (2013) on behalf of the Norwegian nursing association that highlights the need to investigate nurses' knowledge in relation to emergency/disaster plans especially in the community health care system. The paper will explore the conceptual nuances between emergencies and disasters and then comments upon supplementary observations of the need for identifying disaster nursing practices and training programs to prepare nurses. By taking this approach, the paper also seeks to provide insights into how future demands of improving nurses' capacities or implementation as leaders in disaster management - as highlighted by several International studies. In addition, by offering a future research agenda, the intention is that this may contribute to exploration of the role of nursing in handling long-term implications of disaster management.
\end{abstract}

Keywords: community nursing, disaster management plans, disaster nursing, education, nurses' involvement, resilient community.

\section{INTRODUCTION}

Disasters are defined as serious disruptions of the functioning of a community or society that exceeds its ability to cope using its own resources. Disasters have a huge impact on society and many of history's great civilisations have been brought to their knees by the effect of natural disasters according to Coppola [1]. Due to development of new technology, such as air transport and internet, society has become more vulnerable [1, 2]. At present, there is an increase in terrorism, emerging natural threats and even threats of bio-nuclear terrorism [3]. The result of increased urbanization means a rise in the number of people affected when a disaster strikes $[1,4]$. The unexpected may also happen such as the volcanic eruption in Iceland 2010, which paralyzed air transport in Europa for nearly two weeks. Because of these high risks it is important that communities and their local governments build up society's resilience. The present paper investigates Norway, which is a diverse country with both rural and urban regions where a large part of the rural regions lies in the vulnerable area north of the arctic circle. That gives Norway a challenge of building a good resilience in the community. Furthermore, Norway is an affluent country which is a member of UN (United Nations) and ICN (International Council of Nurses). Through these memberships Norway is bound by agreements such as the Sendai Framework for Disaster Risk Reduction [4].

To construct a resilient community there is a need to look at which resources the community have and take these resources into consideration and decide how they could be useful, [5, 6]. Since nurses are the largest healthcare workgroup in the health system their expertise should be taken in to consideration and they should be involved in the disaster planning work [7]. Nurses have, since Florence Nightingale's work with soldiers in the Crimean War been 
linked to provision of care during crises [7]. At that time, Florence Nightingale saw the need for knowledge on how to treat and care for patients and how to prevent sickness. Also today nurses feel there is a lack of specific knowledge in disaster nursing competence [8-10], and where it is important that nurses have skills of disaster related nursing and are involved integrally in all phases of disasters. That also means nurses should be involved in effective preparedness such as planning for a disaster event.

Furthermore, there is a need to strengthen the nurse's skills for involvement in the aftermath of a disaster, the long-term care [7]. This was highlighted in the Norwegian report from nurses' work in the terror event of the 22nd July 2011 [11]. It is necessary to have more drills or exercises at the workplaces and further incorporate such work in the nurses' educational program in Norway and other countries.

The Norwegian government through parliament have decided that there should be disaster management plans and health preparedness plans for each county and for the local community $[12,13]$. These plans are very important for the local government as they set minimum standards in terms of competence across levels of the health care system as well as a minimum level of risk assessment. This is despite the fact that Norway is a large, long and narrow country with only 5.1 million citizens. As shown in Figure 1 the northern part of Norway is located in the arctic and border to Sweden, Finland and northern part of Russia.

Most of the population lives in cities in the southern part of Norway. This means that there are large rural areas with a sparse population. In these regions, it is important that everybody who could be involved, knows what to do if a disaster strikes. For instance, Northern Norway constitutes a third of the Norwegian land mass, but less than $10 \%$ of the Norwegian population live in the Northern part of Norway. It is also a popular region for tourism. The community population in Northern Norway varies from 2000 to 20000 inhabitants with the exception of two towns [15]. Despite such a small population, it is important to have good disaster plans because of the long distances between hospitals as well as the temporary or seasonal population increase that the current expansion in tourism brings. However, the level

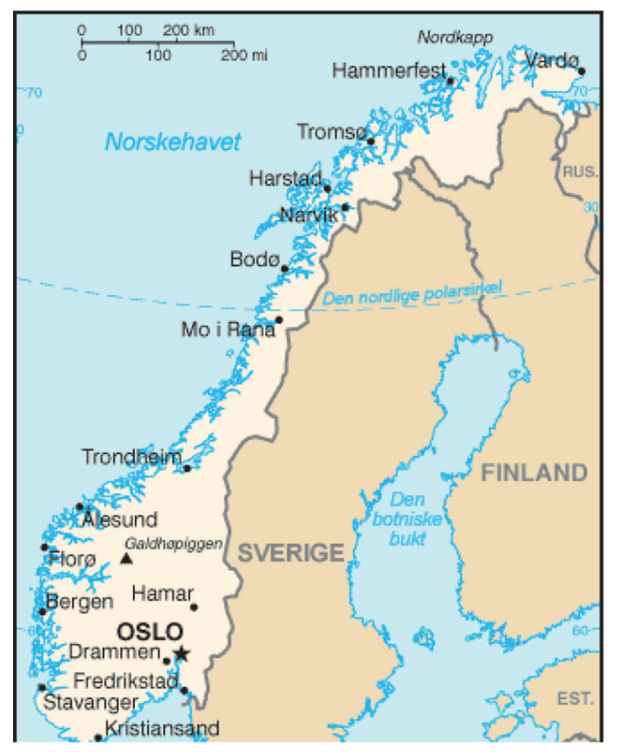

Figure 1: Norway with major towns and its location is shown [14]. 
of services should be the same for the inhabitants anywhere in the country. Consequently, it is important that community nurses are well educated and know what to do when a disaster or a crisis strikes.

\section{BACKGROUND}

Since the time of Florence Nightingale, nurses have contributed to health care to help people in need and are at the forefront of the health care response to disasters [7]. The International Council of Nurses (ICN) defines nurses (short version) as follows:

'Nursing encompasses and collaborative care of individuals of all ages, families, groups and communities, sick or well, and in all settings. Nursing includes the promotion of health, prevention of illness, and the care of ill, disabled and dying people. Advocacy, promotion of safe environment, research, participation in shaping health policy and in patient and health systems management, and education are also key nursing roles' [16].

Nurses are the largest workforce in health care and they play an integral role in disaster response and preparedness according to Veenema et al. [17]. The goal of disaster nursing 'is ensuring that the highest achievable level of care is delivered through identifying, advocating, and care for all impacted populations throughout all phases of a disaster event, including active participation in all levels of disaster planning and preparedness' [7]. With this in mind the role of nursing in handling long-term implications of disaster management, particularly in terms of nursing 'follow-up', is important especially in crisis aftermath. How this work is handled can have a large impact on the people living in the community and therefore also the resilience of the community [7]. In Norway, long-term care is often carried out by health care personnel in the local community. These are often nurses who meet affected people who need nursing care and treatment; there is no automatic follow-up for bereaved people. During a crisis/disaster, crises teams are often appointed based on who should take care of those affected by the event. Yet, when the crisis team is no longer involved, the follow-up process is dependent on the state of the victim/family member, but there are no specific follow-up plans available in the local community. Therefore, there is a need to identify disaster nursing practices and training programs to prepare nurses $[18,19]$. To improve nurses as leaders in disaster management there is a need for more research [17]. This is supported by a Norwegian report by Andrews et al. [11], where findings highlighted the need for a better framework and outlining the length of the 'following-up' process, resourcing requirements and availability and access of competent staff, trained in leading this work in the aftermath of disaster [11, 20]. The aim of the present study is thus to investigate the Norwegian disaster health care plans for nursing expertise and involvement.

\section{METHOD OF DATA COLLECTION}

According to Polit and Beck [21] the investigation of documents and disaster preparedness plans is a method that provides useful insight and data collection. This data could give the researcher an insight to the extent that the nurses may be involved in developing disaster preparedness plans. Furthermore, this investigation will give an understanding of how nursing education in Norway reflects disaster/preparedness work in their curriculum. Data from documents and other non-peer-reviewed publication are also called Grey literature according to Ward-Smith [22], and it provides an alternative source of important information to the study.

This article focused on the Norwegian community nurses involvement in disaster management plans and how the training program prepares nurses for disaster participation and 
preparedness. 'Involvement' is here defined as the nurses' participation in writing the disaster plans, which means that nurses are mentioned, as part of the leadership team, or otherwise. Nursing education prepares nurses for working in the field therefore it should also reflect preparedness for disaster/crises events in their bachelor program. Involvement of nurses in local government disaster management plans can be at a strategic, tactical and operational level. The study of nurses' involvement in community disaster management plans and their training programmes was carried out by the following steps:

1. A review of all community plans in Norway that is available on the internet for the public. The focus has been on the two disaster/crises plans that the community has to have available by an Act of Government [13]. These are the overall disaster management plan and the health preparedness plan. The first is the overall plan where the management (leaders) are involved. The second is the community health preparedness plans [12] where the community nurses could be involved.

2. A review of Norwegian University and University college curriculum for BSc in nursing, as it represents the fundamental education for nurses in Norway.

The scope of disaster management plans in the community process involved reviewing all community plans available on the communities' home pages and cataloguing the involvement of nurses as leaders. This was an internet search on the communities' home pages. The search terms are given in Table 1 with both the Norwegian terms and the English translation.

The search was conducted in November/December 2016 to identify existing disaster and health preparedness plans in the Norwegian communities. Each community home page was studied to determine whether a disaster management plan and a health preparedness plan were available. Furthermore, if one or both plans were available, the next step was to determine if nurses had been involved and their involvement in the communities' crises team.

The internet search for the curriculum of BSc in Nursing was carried out in December 2016 to identify existing courses in disaster or crises management in the Norwegian bachelor program in nursing. Each curriculum was reviewed to determine whether there were courses directly pertaining to disasters.

\section{RESULTS AND FINDINGS}

These results are based on examination of the 428 Norwegian local government home pages in the 19 counties of Norway [23]. According to government regulations and a Government Act, every local government should have disaster management plans [13]. However, this

Table 1: Search terms used in Norwegian communities home pages.

\begin{tabular}{ll}
\hline Norwegian & English \\
\hline Katastrofe & Disaster \\
Krise plan/krisehåndtering & Crises plan \\
Beredskap & Preparedness \\
Overordnet beredskaps plan/Samfunn og sikkerhetsplan & Disaster management plan \\
Helseberedskapsplan/helsemessig og sosial beredskapsplan/ & Health preparedness plan \\
helsemessig beredskapsplan & \\
Kriseteam/omsorgs team & Crises team \\
\hline
\end{tabular}


study shows that there are significant difference in how these plans are presented on the local government home pages and where they are presented (internet or intranet). For instance, some of the home pages have an icon representing preparedness and with one click one can obtain the information. Other local government home pages have no icon at all, and there was a need for carrying out further searches in order to obtain the information. The difficult part was that the necessary key words could also differ from one local government to another despite the words enshrined in the regulation from central government. An example is that whilst the word 'crises team' was the expression used by most of the local government web pages meaning the team that follow-up people who have emotional stress after a disaster or crises, but some web pages used the expression 'care team'. Unfortunately, on some of the local government home pages the information is not available at all. The same findings are also true for the local health preparedness plans.

A number of local governments choose to have their disaster management plans on their intranet rather than on the internet home pages; thus the information about who are involved in their teams are not readily available. Therefore, it has been difficult to be certain if nurses have been involved in the preparation and formulation of the plans. There are only a few cases where it is certain that nurses have been involved.

Another difficulty is that in many of the plans, the people who have been involved are named by their title and not by their profession. That could mean that the person who is the leader of the health department, and in most of the cases this was also a person who was a member of the crises leader team, and have been involved in preparing the plans could be an administrator or a nurse.

The findings from the examination of the local government/communities websites are summarised in Table 2 .

The first column in Table 2 is the name of each county in Norway. The second column is the number of local governments within each county. The third column shows the number of disaster management plans available for the public on the home pages of local governments. The fourth column displays the number of health and social preparedness plans available on the home pages. The fifth column is the number of local governments that have involved nurses in the process of developing one or both preparedness plans. The fifth and final column gives the number of crises teams who have either or both psychiatric nurses or community nurses involved. In a few cases there are also ordinary nurses involved as team members.

In the northern part of Norway there are the three counties Nordland, Troms and Finnmark where the two last counties are north of the arctic circle, whilst Nordland county is divided with one part north and the other part south of the arctic circle. This region of Norway is a third in terms of the area of Norway, whilst the population is 481994 and represents $9,2 \%$ of all Norwegian inhabitants [15], compared to Oslo, the capital, with 658390 inhabitants or $12,57 \%$ of the total Norwegian population [15]. In another comparison, the area of Finnmark county is larger than the whole of Denmark, but the population is much smaller in Finnmark with 75578 and Denmark with about 5707251 inhabitants [15]. Consequently, there are significant differences in the areas that are administrated by the local governments in Norway varying from the very rural in Finnmark to the more urban areas near the capital city, Oslo.

It is seen that not all local governments in the country have disaster management and health preparedness plans available on their home pages. Due to the level of transparency expected it is surprising that there is such a variation. Furthermore, there are no differences in numbers of plans on the home pages between the local governments in rural areas and the local government in more urban areas. There is a variation between counties from $60 \%$ to 
Table 2: Disaster and health management plans for each county in Norway.

\begin{tabular}{|c|c|c|c|c|c|}
\hline County & $\begin{array}{l}\text { Local } \\
\text { government }\end{array}$ & $\begin{array}{l}\text { Disaster } \\
\text { Management } \\
\text { plan (\%) }\end{array}$ & $\begin{array}{l}\text { Health } \\
\text { preparedness } \\
\text { plan. }(\%)\end{array}$ & $\begin{array}{l}\text { Nurses } \\
\text { involved } \\
\text { in plans. } \\
(\%)\end{array}$ & $\begin{array}{l}\text { Nurses } \\
\text { involved in } \\
\text { crises } \\
\text { team. }(\%)\end{array}$ \\
\hline Østfold & 18 & $2(11.1)$ & $2(11.1)$ & $2(11.1)$ & $1(5.5)$ \\
\hline Akershus/Oslo & 23 & $14(60.9)$ & $5(21.7)$ & $5(21.7)$ & 0 \\
\hline Hedemark & 22 & $9(40.9)$ & $2(9.1)$ & $1(4.5)$ & $4(18.2)$ \\
\hline Oppland & 26 & $11(42.3)$ & $17(65.4)$ & $2(7.7)$ & $5(19.2)$ \\
\hline Buskerud & 21 & $13(61.9)$ & $4(19.0)$ & $2(9.5)$ & $5(23.8)$ \\
\hline Vestfold & 14 & $6(42.8)$ & $2(14.2)$ & 0 & $5(35.7)$ \\
\hline Telemark & 18 & $6(33.3)$ & $1(5.5)$ & 0 & $5(27.8)$ \\
\hline Aust-Agder & 15 & $3(20.0)$ & $3(20.0)$ & 0 & $6(40.0)$ \\
\hline Vest-Agder & 15 & $8(53.3)$ & $4(26.7)$ & 0 & $5(33.3)$ \\
\hline Rogaland & 26 & $11(42.3)$ & $5(19.2)$ & $3(11.5)$ & $12(46.1)$ \\
\hline Hordaland & 33 & $8(24.2)$ & $2(6.1)$ & $2(6.1)$ & $16(48.5)$ \\
\hline Sogn og Fjordane & 26 & $9(34.6)$ & $2(7.7)$ & $2(7.7)$ & $14(53.8)$ \\
\hline Møre og Romsdal & 36 & $14(38.9)$ & $4(11.1)$ & $2(5.5)$ & $24(66.7)$ \\
\hline SørTrøndelag & 25 & $9(36.0)$ & $6(24.0)$ & 0 & $11(44.0)$ \\
\hline NordTrøndelag & 23 & $7(30.4)$ & $1(4,3)$ & 0 & $6(26.1)$ \\
\hline Nordland & 44 & $14(31.8)$ & $4(9.1)$ & $3(6.8)$ & $17(38.6)$ \\
\hline Troms & 24 & $5(20.8)$ & $3(12.5)$ & $2(8.3)$ & $6(25.0)$ \\
\hline Finnmark & 19 & $3(15.8)$ & $3(15.8)$ & $3(15.8)$ & $6(31.6)$ \\
\hline Total & 428 & $159(37.1)$ & 68 (15.9) & $29(6.8)$ & $157(36.7)$ \\
\hline
\end{tabular}

$11 \%$ in terms of local government plans available on internet. Also, the nurses' involvement in the development of these plans is very small from $4 \%$ to $15 \%$ between counties. On the other hand, it is seen that nurses are more involved as members of the crises team. The variation is from $5 \%$ to $66 \%$ of local government that have involved nurses in this team. This could mean that nurses are involved mainly at the operational level.

A typical Norwegian BSc nursing education is shown in Table 3.

An investigation of BSc in Nursing at all Norwegian University and University Colleges that educate nurses and postgraduate/master in nurses' related program was carried out in order to detect any Disaster Nursing content. The results of the investigation are shown in Table 4.

The first stage was to investigate if the Norwegian nursing education program involved disaster/crises topic. All of the syllabus appeared to be based on the Norwegian framework for nurses' education [24]. On inspection, the framework does not include any specific reference to disaster nursing topics. None of the university or university college syllabus description appeared to have incorporated disaster nursing topics in the nursing studies. Exception was one MSc where Disaster topic is a part of the syllabus 'Pre-hospital Critical Care'. These syllabi have a module 'Major incident: Medical Management and preparedness' 
Table 3: A Bachelor program in nursing.

\begin{tabular}{|c|c|c|}
\hline 1st Year & $\begin{array}{l}\text { 2nd Year } \\
\text { Preparation, Skills and } \\
\text { Reflection } 2\end{array}$ & $\begin{array}{l}\text { 3rd Year } \\
\text { Preparation, Skills and } \\
\text { Reflection } 3\end{array}$ \\
\hline $\begin{array}{l}\text { Universal Course For Health } \\
\text { Faculty }\end{array}$ & $\begin{array}{l}\text { General pathology, diseases } \\
\text { and pharmacology } 1 \& 2\end{array}$ & $\begin{array}{l}\text { Integrated nursing, sci- } \\
\text { ence and social science }\end{array}$ \\
\hline Preparation, Skills and & Training in Medical or & Nursing, Health and \\
\hline Reflection 1 & Surgical areas 1. Period. & Society \\
\hline $\begin{array}{l}\text { Anatomy, physiology and bio- } \\
\text { chemistry }\end{array}$ & $\begin{array}{l}\text { Training in Medical or } \\
\text { Surgical areas 2. Period. }\end{array}$ & $\begin{array}{l}\text { Training at nursing homes } \\
\text { or psychiatric health care/ } \\
\text { health protection } \\
\text { 1. period } \\
\text { 2. period }\end{array}$ \\
\hline $\begin{array}{l}\text { Foundation nursing with in } \\
\text { ward training and social science } \\
\text { Foundation pharmacology, drug } \\
\text { calculation and handling }\end{array}$ & $\begin{array}{l}\text { Common elements and social } \\
\text { science }\end{array}$ & BSc Final Year Project \\
\hline
\end{tabular}

Table 4: Overview of Disaster Management related topics in nursing education in Norway.

\begin{tabular}{lll}
\hline Institutional Name & Bachelor & Postgraduate/MSc \\
\hline University & & \\
North University & 0 & 0 \\
NTNU & 0 & 0 \\
University in Agder & 0 & 0 \\
University in Stavanger & 0 & Part of MSc in Pre- \\
& & hospital Critical Care \\
University in Troms $\varnothing$ & 0 & 0 \\
University College & & \\
University College Bergen & 0 & 0 \\
University College Stord Haugesund & 0 & 0 \\
University College Molde & 0 & 0 \\
University College Buskerud og Vestfold & 0 & 0 \\
University College Østfold & 0 & 0 \\
University College Hedemark & 0 & 0 \\
University College Oslo og Akershus & 0 & 0 \\
Private University College & & \\
University College Lovisenberg & 0 & 0 \\
University College Diakonova & 0 & 0 \\
University College Høgskulen i Sogn og Fjordane & 0 & 0 \\
University College VID vitenskapelig internasjonal & 0 & 0 \\
diakonal høgskole AS & & \\
Total 16 & 0 & 1 \\
\hline
\end{tabular}


where they highlight terror as an example, and that could indicate that they have disaster management in their education. This is, however, an MSc in the Health Faculty and not specifically for nurses.

\section{DISCUSSION}

Nurses are supposed to deliver an effectively and secured health care based on societies' needs. That should be recognised in the local government's disaster preparedness plans. This is highlighted by Powers et al.: 'An ineffective response can negatively impact on the community's outcome from a disaster by failing to appropriately match nursing resources with need. Nurses must be well versed in strategies for overcoming disaster-induced adversities, and fully understand the different roles they may be required to embrace in order to deliver care effectively in disaster setting'. [7]

This shows the reasons that it is important for nurses to take leading roles in disaster teams. These reasons are in summary:

- Matching nurses' resources with need, the Nursing leader know the nurses skills and can therefore order them to correct location.

- Nurses must be well educated and understand their roles in a disaster setting.

Norway, like a large number of countries, is a member of the International Council of Nurses (ICN), which promotes the concept of disaster nursing [25]. Furthermore, because Norway is largely rural with long distances between hospitals and in some regions, it is also far between medical practitioners it may take a very long time for them to reach a disaster area. Consequently, it is even more important in the remote regions that nurses have both medical and disaster management skills and be involved in strategic, tactical and operational roles. Examining the results with this in mind, several comments can be made.

Table 2 demonstrates that very few nurses are included in local government disaster planning teams. In most of the teams, the leader of health and social provision is a member of the team. It is not clear from the information available that these persons have background as nurses. Nevertheless, it is known that the leaders of the health and social provision may not be nurses.

The main aim of the disaster management plan is to prepare the inhabitants and reduce future risk in local government [26]. In Norway there is a Government requirement [13] that every local government should have a disaster preparedness plan. According to the Norwegian Directorate for Civil Protection and Emergency Planning (DBS), 94\% of local governments have a disaster preparedness plan [23]. This agrees with the Norwegian NF rapport from 2012 [11] and could mean that the level has not improved. Only 59\% of 428 local governments fulfil the requirements for updating plans once a year [23]. This should also be seen in the light of the population size in some of the local government regions. The smaller regions may only have a few thousand inhabitants. These rural regions are also located far from hospitals with an Accident and Emergency Department (A\&E). Furthermore, in recent years many of the smaller hospitals have been stripped of their A\&E department which has been transferred to larger hospitals further away from the smaller rural populations. It is still government policy in Norway to centralise A\&E provision in order to make healthcare more efficient. In the Northern rural areas transport both by road and air is very challenging during the winter months. Weather conditions often make it impossible for helicopters to fly and transport by road could be slow or impossible because of snow and ice. 
However most of the local governments have established psychosocial crises team and $37 \%$ nurses are involved in these teams. This is underlined by the Norwegian NF report [11], where $42 \%$ of the nurses were members of the psychosocial crises team and $25 \%$ were leaders of the crisis management team. Importantly, information extracted from the report shows that most of the informants come from urban areas. Consequently, it is presently even more important that nurses working in rural areas are well educated, trained and prepared [27]. The planning team of the preparedness plan should clearly contain nurses due to their knowledge of how to use the nursing resources in a crisis. This raises the question about why the nurses are not more visible in the planning of preparedness plans? Does it mean that nurses are seen as support staff only? Or does it mean that managers of local government do not have sufficient knowledge related to the skills that nurses have? Or finally does it mean that nurses need better education related to nursing disaster skills?

The result of the present study (Table 3) suggests that the Norwegian framework for nurses does not include any specific reference to disaster or disaster preparedness topics despite the fact that a large part of Norway is rural and disasters may happen anywhere. The Norwegian NF report [11] also shows that only 2,48\% have sufficient knowledge about handling a crises or disaster based on BSc in nursing. The same findings were conclusions of a literature study by Rokkas and Steenkamp [28]. The Norwegian NF report [11] also shows that a little more, $3,09 \%$, have competence in crises/disaster work from postgraduate education. Whilst there is an apparent need for disaster related topics in Norwegian nurses' education, this need for implementing disaster nursing topics is also proposed by several international nursing groups $[10,17,19,27,29,30]$. A way forward in Norway could be to introduce Disaster Nursing topics within the Norwegian National Framework so that Nurses in general would have an understanding and background in Disaster Nursing. Involvement in disasters means strategic, tactical and operational roles. The future development of Nurses education should reflect this. To meet the future requirements in dealing with disaster and crises events, an MSc in Disaster Nursing is suggested in order to aid community resilience. This is also underlined by the NSF report [11]. However, it is possible that topics relevant to disaster nursing work may be part of other subjects such as those for A\&E nursing. In order to investigate this, it is necessary to have available the details of each programme.

It is clear that disaster management will be strengthened by including nurses in the planning and management in the disaster management teams. This is also suggested by Miles [31]. This is especially important in rural and sparsely populated areas where the community nurse may be the only person representing the whole of the medical profession. In addition, there is a trend to centralise services such as A\&E departments, this means that such services, as well as those pertaining to psychiatry, will be few and far between. Consequently, nurses in these communities will have a larger job description than what is presently the case. The need for a re-evaluation of their training to include disaster nursing topics as part of the BSc in nursing is certainly important in order to provide the same health care as in the cities, both for those living in rural areas and those visiting such regions. Developing standards and guidelines for incorporating disaster management and training in nursing education was in 2009 one of the highest priorities in ICN [25], and should certainly be the case for Norway.

\section{CONCLUSION}

The data available for the present study suggest that nurses have been less involved in disaster preparedness work than what would be expected since they represent the largest group of health workers in the community. It is suggested that they should be present to a much greater extent. 
However, nurses with postgraduate education such as psychiatry and public health are found in crises teams.

Furthermore, the curriculum for the Norwegian BSc in Nursing does not include specific topics related to preparedness and disaster management. It is suggested that a revision to include such topics should be carried out.

Other conclusions are that the homepages for local government differ greatly between the communities. It is recommended that such homepages should be standardised in order to assist transparency and so that the public can easily find the information they need in a disaster/crises situation. Similarly, the terminology used by local government is also quite varied. Again, it is recommended that such terminology should be standardised so that the public can easily find the information they need in a disaster/crises situation.

\section{FURTHER WORK}

This study has highlighted the challenges that Norwegian community nurses have to meet in order to be prepared for disaster/crises. Furthermore, the study may indicate that the differing challenges from region to region or from rural area to urban area are not adapted to the community nurses work. To clarify this, the authors agree that the future research agenda of this work has to consider the following:

1. Further investigate if there are a minimum level of standards for all community nurses working in Norway.

2. Investigate the expectation regarding skills of nurses in risk assessment and disaster management at different levels for the various and diverse regions.

3. Further analyse how and where nurses are represented in local government disaster preparedness plans.

4. Investigate if nurses are represented in the strategic, tactical and operational level.

More broadly in terms of community resilience, exploring this agenda will help shape the need for nurses' special skills; what should be called disaster community nurses. If we can understand the need for nurses with special skills, then we can consider whether present day nursing education is adequate and take care of what local government can expect from them.

\section{REFERENCES}

[1] Coppola, D.P., Introduction to International Disaster Management, 3rd edn., Butterworth-Heinemann, Elsevier: Oxford, 2015.

[2] Comfort, L.K., Boin, A. \& Demchak, C.C., Resilience revisited: an action agenda for managing extreme events. Designing Resilience Preparing for Extreme Events, eds L.L. Comfort, A. Boin \& C.C. Demchak, University of Pittsburgh Press: Pittsburgh, pp. 272-284, 2010.

[3] Boin, A., Hart, P., Stern, E. \& Sundelius, B., The Politics of Crisis Management: Public Leadership Under Pressure, Cambridge University Press: USA, 2005. https://doi.org/10.1017/CBO9780511490880

[4] United Nations Office for Disaster Risk Reduction (UNISDR) 2015. Sendai Framework for Disaster Risk Reduction 2015-2030. United Nations - Headquarters.

[5] Comfort, L.K., Oh, N., Ertan, G. \& Scheinert, S., Designing adaptive systems for disaster mitigation and response: The role of structure. Designing Resilience Preparing for 
Extreme Events, eds L.K. Comfort, A. Boin. and C.C. Demchak, University of Pittsburgh press: Pittsburgh, pp. 33-61, 2010.

[6] Hunter Revell, S.M. \& McCurry, M.K., Postflood disaster management and the home health nurse: using theory to guide practice. Journal of Community Health Nursing, 27, pp. 126-136, 2010.

https://doi.org/10.1080/07370016.2010.494454

[7] Powers, R., Introduction to disaster nursing. International Disaster Nursing, eds R. Powers \& E. Daily, Cambridge University Press: New York, pp. 1-11, 2010. https://doi.org/10.1017/CBO9780511841415.004

[8] Yan, Y.E., Turale, S., Stone, T. \& Petrini, M., Disaster nursing skills, knowledge and attitudes required in earthquake relief: Implications for nursing education. International Nursing Review, 62, pp. 351-359, 2015.

https://doi.org/10.1111/inr.12175

[9] Chapman, K. \& Arbon, P., Are nurses ready? disaster preparedness in the acute setting. Australasian Emergency Nursing Journal, 11, pp. 135-144, 2008. https://doi.org/10.1016/j.aenj.2008.04.002

[10] Nilsson, J., Johansson, E., Carlsson, M., Florin, J., Leksell, J., Lepp, M., Lindholm, C., Nordström, G., Theander, K., Wilde-Larsson, B. \& Gardulf, A., Disaster nursing: Self-reported competence of nursing students and registered nurses, with focus on their readiness to manage violence, serious events and disasters. Nurse Education in Practice, 17, pp. 102-108, 2016.

https://doi.org/10.1016/j.nepr.2015.09.012

[11] Andrews, T., Gustavsen, A., Waldahl, R.H. \& Eide, A.K., The role and action of nurses in a national catastrophy. About the work with victims of the event 22nd July 2011. Bodø: NF- rapport. 2013. (in Norwegian) ISBN-nr.:978-82-7321-639-7

[12] Health Preparedness Act. (Act No. 56 of 23 June 2000 relating to health and social preparedness.), available at www.lovdata.no (accessed 4 November 2016) (In Norwegian)

[13] Civil protection Act. (Act of 25 June 2010, No. 45 relating to municipal preparedness duty, civil protection and the Norwegian Civil Defense), available at www.lovdata.no (accessed 4 November 2016) (In Norwegian)

[14] Statens Kartverk available at www.norgeskart.no (accessed 22 December 2016).

[15] Statistics Norway available at https://www.ssb.no (accessed 15 December 2016).

[16] International Council of Nurses, 2002. Definition of Nursing 2 (short version). available at http://www.icn.ch/who-we-are/icn-definition-of-nursing/ (accessed 12 December 2016).

[17] Veenema, T.G., Griffin, A., Gable, A.R., MacIntyre, L., Simons, R.A.D.M., Couig, M.P., Walsh, J.J., Lavin, R.P., Dobalian, A. \& Larson, E., Nurses as leaders in disaster preparedness and response- a call to action. Journal of Nursing Scholarship, 48(2), pp. 187-200, 2016.

https://doi.org/10.1111/jnu.12198

[18] Bahrami, M., Aliakbari, F. \& Aein, F., Iranian nurses' perception of essential competences in disaster response: A qualitative study. Journal of Education and Health Promotion, 3, p. 81, 2014.

[19] Yamamoto, A., Development of disaster nursing in Japan, and trends of disaster nursing in the world. Japan Journal of Nursing Science, 10, pp. 162-169, 2013. https://doi.org/10.1111/jjns.12042 
[20] Lereim, I., et al., Learning for improved emergency preparedness. Health intervention after the terror event 22 July 2011, Directorate of Health, Oslo, 2012. (In Norwegian) ISBN-nr. 978-82-8081-256-8

[21] Polit, D.F. \& Beck, C.T., Nursing research Principles and Methods, 7th edn., Philadelphia: Lippincott Williams \& Wilkins, 2004.

[22] Ward-Smith, P., The fine print of literature reviews. Urologic Nursing, 36(5), pp. $253-$ 258. 2016.

[23] Norwegian Directorate for Civil Protection and Emergency Planning (DBS), Local government study 2016. (In Norwegian), available at https://www.dsb.no (accessed 5 November 2016)

[24] Norwegian government department of education and research. Framework for Nurses education, 25 January 2008. (In Norwegian) available at www.regjeringen.no

[25] World Health Organization and International Council of Nurses 2009. ICN Framework of Disaster Nursing Competencies. Available at: www.icn.ch/ (accessed 9 November 2016)

[26] Alexander, D., Principles of Emergency Planning and Management, Terra Publishing: United Kingdom.

[27] Baack, S. \& Alfred, D., Nurses' preparedness and perceived competence in managing disasters. Journal of Nursing Scholarship, 45(3), pp. 281-287, 2013. https://doi.org/10.1111/jnu.12029

[28] Rokkas, P. \& Steenkamp, M., Disaster preparedness and response: Challenges for Australian public health nurses - A literature review. Nursing and Health Sciences, 16, pp. 60-66, 2014. https://doi.org/10.1111/nhs.12134

[29] Usher, K., Redman-MacLaren, M.L., Mills, J., West, C., Casella, E., Hapsari, E.D., Bonita, S., Rosaldo, R., Liswar, A.K. \& Amy, Y.Z., Strengthen and preparing: Enhancing nursing research for disaster management. Nurse Education in Practice, 15, pp. 68-74, 2015.

https://doi.org/10.1016/j.nepr.2014.03.006

[30] Schmidt, C.K., Davis, J.M., Sanders, J.L., Chapman, L.A., Cisco, M.C. \& Hady, A.R., Exploring nursing students' level of preparedness for disaster response. Nursing Education Perspectives, 32(6), pp. 380-383, 2011. https://doi.org/10.5480/1536-5026-32.6.380

[31] Miles, L., The 'Five-C's': international disaster management and public health and place for entrepreneurial resilience. Perspectives on Public Health, 136(6), pp. 323 325, 2016.

https://doi.org/10.1177/1757913916672810 